\title{
Jose Yglesias: el cronista / dramaturgo de Ybor City (Tampa) ${ }^{1}$
}

\section{Beatriz J. Rizk}

El legado literario de Jose Yglesias (1919-1995) consiste de ocho novelas, cuatro libros de relatos, cuatro obras de teatro e innumerables ensayos, cuentos, artículos y reseñas. Fue un hombre dedicado a las letras entrando al teatro solamente en su última etapa; su fuerte fue la narrativa y el periodismo. ${ }^{2}$ Como enviado especial del New York Times, para el que colaboró durante varios años, fue a España, Cuba y América Latina, dejándonos libros que hasta hoy en día son de referencia importante para la época como The Franco Years (1976). Fue también traductor; entre las novelas que tradujo se encuentran Island of Women de Juan Goytisolo y Villa Milo de Xavier Domingo, ambas publicadas en 1962. Yglesias nació en West Tampa y se crió en Ybor City; en 1937 se mudó a Nueva York en donde pasó el resto de sus días, lo que no lo excluye de haber sido y seguir siendo considerado como el "autor más importante que ha producido Tampa" (Ingalls, "The Life" 6). Y esto se debe, sin duda, a haber dedicado la mayor parte de su obra a tratar de que "los lectores [norte]americanos conozcan Ybor City y sus tabacaleros latinos". De hecho, él mismo cuenta como, "the moment I wrote and published my first story immediately after the [Second World] war [...] Ybor City, the Latin island in Tampa (the word ghetto does not fit it) was my subject" ("A Trilogy", 5). Pero no se trataba solamente del vecindario de la ciudad de Tampa que lleva este nombre, fundado en 1885 por Vicente Martínez Ybor (1818-1896), un empresario tabacalero cubano con empresas en Cayo Hueso (Key West) y La Habana, sino de su propia familia, tres generaciones de los Milián empezando por la que llegó de La Habana, de parte de su abuela materna, y de Matanzas, vía Cayo Hueso, del abuelo materno, una vez fundadas las tabacaleras. La ironía más grande de esta historia, y el contexto en el que se desarrollan las obras, es que Martínez Ybor fundó la tabacalera en Tampa para escapar de los problemas laborales que ya plagaban sus empresas en las 
ciudades mencionadas antes pero como tenía, para su funcionamiento, que importar trabajadores especializados, esperando, como dice Yglesias y por supuesto inútilmente, que el cruce del golfo desde las dos islas los "fumigara ideológicamente", terminó llevándose con él los mismos problemas. De hecho, antes de que abriera la tabacalera, los trabajadores ya habían entrado en huelga. Ybor City se convirtió, como nuestro autor señala, en una "isla Latina", aunque tendríamos que añadir en una isla "radical" Latina, separada de los norteamericanos (a los que ellos llamaban "crackers" y por falta de mejores términos "bárbaros") del otro lado de la Avenida Nebraska.

Ahora, hay que tener en cuenta que Yglesias escribe (y en este sentido se acerca prodigiosamente a Tennessee Williams) desde el tiempo presente, o sea cuando ya Ybor City (como el sur al que se refiere el autor norteamericano), tal como él la conoció y la vivió durante su niñez y adolescencia y a través de sus innumerables viajes de regreso a visitar parientes, no existe. Además hay un desdoblamiento espacial interesante en la memoria de estos personajes porque la Cuba a la que ellos también se refieren, en sus conversaciones diarias, tampoco existe; es un producto de sus recuerdos. El tiempo no se detuvo en Ybor City, ni física ni metafóricamente; al contrario, al igual que las huelgas a las que se refiere en su teatro y novelas, sus habitantes, al parecer, perdieron todas sus batallas. Un sentido de derrota social permea las obras, pero es su lucha la que importa y lo que redime la historia, ese capítulo de la saga cubano-americana y de la historia norteamericana, con diferentes signos, la que él intenta plasmar a través de su obra. "I believe literature is the grand repository of our best feelings and ideas" (cit. por Ingalls, "Jose Yglesias", 81), nos dice, y lo lleva a cabo al tratar de "memorizar" Ybor City, representada por lo que él considera "el mejor grupo de trabajadores organizados en [la] América" de su tiempo. En realidad, su obra es absolutamente autobiográfica; de hecho, hay poco material conocido sobre la vida de sus antepasados que no haya llevado a la ficción, y luego al teatro, y casi no hay nada en su ficción y en su teatro que no haya sido parte de su vida. ${ }^{3}$

¿Y quiénes eran estos trabajadores? Eran cubanos y españoles, como el padre de Yglesias de origen gallego quien fue enviado cuando tenía 13 años a Cuba (en 1902) para ser aprendiz de tabacalero, y sicilianos. Venían todos de un medio revolucionario (y valga la generalización) porque no solamente estaba Cuba en pleno período independentista - por eso la presencia de José Martí históricamente, como constata las obras, fue fundamental para mantener la ideología que desde un principio adoptaron los trabajadores - , sino también los italianos aportaron a su perfil ideológico pues eran anarquistas. Era la 
época, y no sólo en Cuba, sino en América Latina igual, en que los sindicatos tomaron auge y se politizaron completamente, lo que significó que apoyaron los movimientos de una izquierda revolucionaria con vientos "renovadores" europeos en la que el anarquismo tuvo una presencia esencial. Sin ir muy lejos, y para poner el período histórico en contexto, la revolución mexicana que marcó toda la primera década del siglo XX se inició propiamente con las ideas anarquistas de los hermanos Flores Magón (Enrique y Ricardo, quien también fue dramaturgo; ver Marcela de los Ríos). En la literatura y en el teatro latinoamericano, el anarquismo suplió el fondo ideológico de muchos de nuestros clásicos de principios de siglo, empezando con el rioplatense Florencio Sánchez. En Chile, Antonio Acevedo Hernández, llamado "padre del teatro chileno", funda en 1913 "la primera compañía de teatro totalmente chilena, con aficionados del sindicalismo anarquista" (Muguercia 95). Durante el auge saineteril de principios de siglo argentino, en la obra Los disfrazados de Carlos Pacheco (1906), uno de los mayores exponentes del género, se menciona a Kropotkin (Pyotr Alexayevich Kropotkin [1842-1921]), el llamado "príncipe anarquista" (porque lo era) cuyos escritos tuvieron amplia repercusión en el mundo occidental, mencionado en las obras de Yglesias. Y los ejemplos se multiplican; sin embargo, creemos que la importancia que tuvo el anarquismo como doctrina y como influencia en el primer drama social latinoamericano no ha sido explorada con profundidad. ${ }^{4}$

En Cuba, el antecedente directo lo encontramos en José Antonio Ramos, con su obra Tembladera (1917), en la que el autor sale en defensa de la nacionalidad cubana en vista a la considerable interferencia de los Estados Unidos en el país, mediando ya la Enmienda Pratt (Garzón Céspedes 5). Pero quizás, el elemento más importante de la obra de Ramos, para nuestro tema, fue el "mostrar un conflicto de trascendencia nacional a través del microcosmos familiar", un "recurso", como bien dice Carlos Espinosa Domínguez, "que aparecerá de manera constante y repetida en buena parte" de la dramaturgia cubana de este siglo (15), como es el caso aquí. Por otra parte, el marco de referencia ideológico en el que se sitúa tanto Yglesias como su obra es importante debido a que, siendo de origen cubano-español, aunque a su padre dejó de verlo a la edad de 5 años y se crió con su madre y abuelos de la familia materna, siempre se vio obligado a definirse en términos ideológicos, a lo que él respondía sin vacilar, apelando al capital simbólico que heredó de sus antepasados: "My background was very class-conscious radical. You know how people say 'I vote Republican because my parents did'? I'm a socialist because my parents were socialist. [...] What was good 
enough for my folks is good enough for me" (cit. por Ingalls, “The Life", 9). Es evidente que el caso de Yglesias ilustra las premisas establecidas por el sociólogo Pierre Bourdieu en su trabajo seminal Distinction: A Social Critique of the Judgement of Taste, en el que señala: "The native world is, above all, the maternal world, the world of primordial tastes and basic foods, of the archetypal relation to the archetypal cultural good" (79).

Los tabacaleros que llegaron a Tampa a finales del siglo XIX, y por el lapso de por lo menos dos décadas, mostraron una capacidad extraordinaria de organización social y política. ${ }^{5}$ Fundaron clubes - entre ellos el Círculo Cubano, el Centro Español, el Centro Asturiano (siendo uno de los más importantes era una extensión del Centro Asturiano de La Habana) y la Sociedad Siciliana-que se convirtieron en centros sociales claves para la cohesión cultural de la comunidad no sólo en el aspecto didáctico sino el del "entretenimiento" (como decimos hoy en día). Sabemos, por ejemplo, que cuando Enrico Caruso visitó Tampa fueron los tabacaleros los que lo contrataron. Cuando se impusieron oficialmente las leyes de "Jim Crow" en la Florida durante la primera década del siglo $\mathrm{XX},{ }^{6}$ dando paso a la segregación en firme de la población de color (según los legisladores se trataba de condiciones iguales pero en sitios separados), ésta fundó el centro Martí-Maceo, pues pese a la resistencia general de la población (latina) a cumplir las leyes, se veían obligados a negarles a los negros la entrada en algunas funciones bajo penas de encarcelamientos y multas. ${ }^{7}$ Construyeron hospitales y pagaban los médicos a través de una mensualidad mínima, lo que inmediatamente trajo la oposición de las asociaciones norteamericanas reguladoras del segmento de la salud pública en el país. Establecieron una unión, que no fue apoyada ni reconocida por el movimiento sindicalista norteamericano pero sí por el cubano - se hacían contribuciones y colectas mutuas cuando los trabajadores de un lado o del otro del golfo entraban en huelga.

Los tabacaleros trajeron consigo además, lo que fue absolutamente fundamental para el desarrollo cultural de la comunidad, el hábito de los lectores (llevado al teatro exitosamente por Nilo Cruz, en Ana en el trópico). La primera lectura en La Habana tuvo lugar en la tabaquería "El fígaro" en diciembre de 1865. Casi simultáneamente se inauguraron en la fábrica Partagas (por mencionar sólo dos de las más importantes); se estima que para 1865 existían 500 tabaquerías en la ciudad con cerca de 15,000 artesanos trabajando (Tinajero). La historia de los lectores en las tabaquerías cubanas refleja las vicisitudes por las que estaba pasando el teatro vernacular; unos meses después de inauguradas las lecturas, se prohibieron oficialmente por 
"distraer" con "discusiones extrañas" a los tabacaleros en su trabajo. Se reanudaron en 1868 y sufrieron la misma suerte que el "bufo" (ver Leal), al ser desterradas por 12 años hasta 1880. Asimismo, tenemos noticias de la entrada de los lectores a las tabacaleras de Cayo Hueso en 1868. De manera que estos trabajadores, algunos de ellos analfabetos, estaban versados tanto en la literatura universal en boga durante la época —-leían a Tolstoy, Zola, Balzac, entre otros - como en el teatro. En Cuba, un lector de tabaquería, Ramiro de Maeztu, dejó un testimonio, con fecha de 1902, en el que habla del interés que despertaron los dramas de Ibsen, "autor apoyado en los círculos anarquistas", en los tabacaleros (Mugercia 85-86). El caso es que los trabajadores mismos financiaban las lecturas; en Tampa pagaban 25 centavos a la semana de su sueldo para emplear a los lectores, escogidos democráticamente por ellos mismos así como el material que se leía. Se dedicaban cuatro horas al día a las lecturas, dos a la literatura y dos a periódicos; estos eran publicaciones anarquistas. Uno de los autores preferidos era ciertamente el mencionado Kropotkin, hasta que, como relata el mismo Yglesias, Estados Unidos entró en la Primera Guerra Mundial y de ahí en adelante, teniendo de por medio la Revolución Rusa, se incluyeron periódicos radicales como el New York Daily Worker, que el lector traducía simultáneamente del inglés. Los lectores eran generalmente personas destacadas de la comunidad. El tío de Yglesias, Francisco Milián, fue lector y llegó a ser el primer alcalde latino de la ciudad de West Tampa, razón por la cual, según cree Yglesias, después de su mandato se incorporó West Tampa a Tampa, para que ningún otro cubano volviera a ser alcalde.

De manera que las huelgas se convirtieron en un modus operandi de esta comunidad que no dudó en lanzarse a la calle frecuentemente a defender sus derechos durante todo este período - sabemos sobre la larga huelga de 1901; en 1910 hubo otra que duró doce meses; en 1920 otra que duró diez meses y en 1931 entraron en huelga cuando los propietarios de las tabaquerías decidieron terminar definitivamente con el hábito de los lectores. Está por demás decir que a pesar de la larga duración perdieron todas las huelgas; casi siempre se resolvían por la fuerza con la ayuda del Ku Klux Klan, ante la mirada impertérrita de la policía y las autoridades locales. Pero su compromiso político no se redujo a los conflictos locales; en 1937 el pueblo entero se volcó a las calles en apoyo de las fuerzas republicanas en España. Según Yglesias (y no hemos podido comprobarlo) el himno que cantaban los republicanos "No pasarán", lo compuso un cubano de Tampa. ${ }^{8}$ El compromiso de los tabacaleros con el pueblo español surgía del convencimiento de que 
las fuerzas contra las que luchaban - la aristocracia, la iglesia y el sector militar - eran las mismas que "originally led the Spanish to emigrate and the Cubans to fight for independence" (Yglesias, "The Bittersweet Legacy", 56). De hecho, al mismo tiempo que coloca a Ybor City y sus habitantes bajo la mirilla, Yglesias enfatiza el papel histórico que desempeñó esta comunidad en la trayectoria política de Martí, subrayando su paso por Tampa en 1891 y 1892, cuando dio dos discursos memorables, especialmente el segundo conocido como "Los pinos nuevos", a los que tenemos acceso hoy en día porque uno de los lectores los tomó taquigráficamente. ${ }^{9}$ Cuando regresa a Nueva York y da cuenta, en un reportaje, sobre lo que aprendió en Tampa, el líder independentista declara: "Lo que tengo que decir antes de que se me apague la voz y mi corazón cese de latir, es que mi patria posee todas las virtudes necesarias para la conquista y mantenimiento de la libertad" (cit. por Yglesias, "José Martí”, 62). Las resoluciones para su recién fundado Partido Revolucionario, en ese año de 1892, fueron escritas en Tampa y aprobadas por voto antes de su viaje a Nueva York.

[I]n my family throughout the years of my growing up - from the Twenties on-Martí was a living presence. They had heard him speak, and my Cuban grandfather, Rafael Milián, had lived in New York and Key West, too, in the years that Martí had worked and lived in one and visited the other. (62)

En las obras, sobre todo las dos primeras de la trilogía que visitaremos aquí, se habla de él constantemente como si se tratara de un pariente muerto. ${ }^{10}$ De hecho, Yglesias colabora con un esclarecedor ensayo sobre el líder que pasó más de la tercera parte de su vida en suelo norteamericano en un libro llamado José Martí in the United States: The Florida Experience, en el que examina su misión a luz de los apelativos que se le atribuyeron como el de "apóstol" y el de "profeta de Tampa" (este último en boca de Esteban Montejo, el esclavo fugitivo en Biografía de un cimarrón (1966) de Miguel Barnet), haciendo hincapié en su inspiración popular cuando toma partido y emite los famosos versos "con los pobres de la tierra quiero yo mi suerte echar" en sus célebres Versos sencillos ("José Martí”, 59-71), adelantándose casi en un siglo a la Teología de la Liberación (con la preferencia opcional por los pobres).

Por otra parte, hay que entender que esta comunidad no vino en busca de ningún "sueño americano". Su integración o no integración a una supuesta "cultura americana" no estaba en sus planes, de ahí el título de la primera obra de su trilogía sobre Ybor City Chattahooche, que es el nombre de la institución mental más importante de la Florida durante décadas, 
refiriéndose metafóricamente al país del norte y al imbalance mental en que su progenie quedaría ante su ya aparente imposible regreso a la isla. ${ }^{11}$ Como la mayoría en la segunda comunidad en el exilio en suelo floridiano que se formó décadas después en Miami, estos cubanos no vinieron para quedarse:

LOLA. Don't worry my dear. I've got plans. We don't have to stay here in Tampa. We never meant to when we were young - as soon as Martí and Maceo liberated Cuba we'd take our family of girls to Cuba. $(14)^{12}$

Para todos estos trabajadores, el final de la lucha independentista con la interferencia norteamericana fue devastador, tal como Gustavo, el abuelo, en la primera obra, comenta con Lola, su mujer:

GUSTAVO. Well then, it's a romantic dream of yours, this going to Cuba.

LOLA. When Martí was alive, that was your dream.

GUSTAVO. In an independent and free Cuba. It belongs to Uncle Sam now. Might as well stay here. (24)

Las conversaciones en los porches de Ybor City todas las noches, mencionadas en las obras, se desarrollaban alrededor de los mismos temas: los pormenores de la saga libertaria cubana; se hablaba de Martínez Campos, el general español quien fue gobernador de Cuba cuando se firmó la Paz de Zanjón que diera fin a la "Guerra de los 10 años" en 1878, de si tuvo éxito o no; de Maceo y Máximo Gómez; del por qué Martí regresó a Cuba y entró en la contienda. De ahí, como señala Yglesias,

It's a telling comment on the sadness of the outcome of the struggle for Cuban independence that these workers who had gathered round Martí [...] — these workers who first inspired him to believe that the time was ripe for revolution did not go back to the island, when, as my grandfather used to say, el politiqueo began; that is after the Constitution with its Pratt Amendment was in place and presidential elections began. ("José Martí", 63)

La sociedad se dividía nítidamente en dos, los Latinos de un lado y los norteamericanos del otro; "When Americans got mad at any Latin, he called him a 'Cuban nigger"” (cit. por Ingalls, "The Life", 12). ${ }^{13}$ Experimentó muy joven la vergüenza asociada con la etnicidad, cuyo arrepentimiento y proceso de "concientización" sin duda fue una de las razones que lo impulsó a dedicarse a esa comunidad que dejó tan joven. A los 12 años ("I was stubbornly intent on being American" [12]), quería desesperadamente ser americano como sus compañeros de clase en el High School. En cuanto se 
graduó y tuvo la oportunidad de partir, se fue para Nueva York para dejar atrás no solo a Ybor City sino también su legado cultural - hasta trató ya en la ciudad del norte de cambiarse el nombre por uno que sonara norteamericano. Este proceso experimentado por Yglesias es uno ya bastante usual en el individuo de origen latino en el país del norte. ¿Qué pasa cuando los dos contextos fundamentales en el crecimiento de un individuo, la familia y la sociedad que lo rodea, son disonantes, cuando en vez de validarse el uno al otro se anulan, cuando el capital simbólico adquirido, en el sentido que le brinda el mencionado sociólogo Bourdieu, por su implícita arbitrariedad no puede convertirse en una "inversión cultural" que le dé sentido a su paso por el mundo? En el caso de Yglesias fueron dos los factores que le brindarían norte a su vida y marcarían el sino que seguiría su trayectoria como escritor: a saber, la huelga en contra de la abolición de los lectores en las tabacaleras en 1931 (¿Cuándo, se preguntaría él más adelante, se ha visto en la historia laboral y sindicalista del mundo a unos trabajadores que vayan a un paro en defensa de la cultura?) y el compromiso que asumió la comunidad cubana tanto de Ybor City como de Nueva York ante la Guerra Civil Española del lado de los republicanos ("It was through Spain that I, like many of my generation, began to know and judge the world" ["The Bittersweet", 57]). De ahí que al entrar Estados Unidos en la Segunda Guerra Mundial, Yglesias se alistó en el ejército para ayudar a defender el mundo de la amenaza que representaba el fascismo europeo.

Este es el contexto de la trilogía de Yglesias que consta de la primera obra mencionada antes llamada Chattahooche, que tiene lugar en 1912; The Dictatorship of the Proletariat, que sucede en 1920 después de la Revolución Rusa, de ahí su nombre, y la tercera You Don't Remember? que tiene lugar en diciembre de $1978 .{ }^{14}$

Dentro de los parámetros del mejor teatro anarquista, la dramaturgia de Yglesias se centra alrededor de un "problema universal: el conflicto del individuo y la organización social" (Lamus Obregón 231). Los personajes de sus obras son tabacaleros, y esa mentalidad proletaria definida por los conflictos laborales, aunque en constante pugna con otras clases aun dentro de la misma familia, como veremos, unido al antagonismo palpable de la sociedad receptora que contribuyó a que se conformara en una comunidad solidaria y auto suficiente en muchos sentidos, es de lo que tratan las piezas. ${ }^{15}$

La primera pieza se centra alrededor de la familia de sus abuelos maternos, los ya mencionados Gustavo y Lola Milián; ella ya ha pasado los cincuenta y él tiene diez años menos. De las varias hijas que conciben 
sólo entra en la escena la hija menor Leonora (madre del autor) junto con la mayor María Luz (a quien llaman Titi), hija de Lola, anterior al matrimonio con Gustavo, razón por la cual ella se va de La Habana a vivir a Nueva York donde lo conoce. Completa el cuadro familiar el marido de Titi, Alejandro, quien sufre de depresión mental y alrededor del cual se desarrolla el conflicto de la obra, pues es al que deciden finalmente recluir en Chattahooche. También entran a colación Consuelo, una medio hermana negra de Lola, antigua esclava suya; Ramón Ybarra, novio de la hija menor, de origen gallego (el padre del autor, quien se casa con su madre en 1913) y el Dr. Ayala, un médico del programa del Club Cubano.

La presencia en la obra de un personaje afro-descendiente, en una época histórica conocida por el racismo llevado al extremo, pone sobre el tapete las diferencias entre las dos comunidades - la cubana y la anglosajona circundante - ante el problema racial. De hecho, el personaje de Consuelo está también basado en un personaje de la vida real: la mujer del famoso tío Francisco era negra. A sabiendas que estaba prácticamente violando la ley por contraer un matrimonio interracial se casó con ella y tuvo dos hijos. La obra empieza con Consuelo haciendo una limpia por toda la cocina. Viene a contarle a Lola cómo a sus dos hijos, por primera vez, les negaron la entrada a un baile en el Club Cubano. A lo que Lola responde:

LOLA. [...] Why didn't they hit back? (Stares at Consuelo, but gets no answer). They call it the Cuban Club and they let these Americans tell them who is Cuban and who is not! It's time we all went back to Havana. Gustavo will have to face me head-on now, no more nostalgic talk, we go back.

CONSUELO. I didn't mean-

LOLA. And you, will you really leave with your sons?

CONSUELO. It's the law here. That's what they told my boys. Sir, are you going upstairs to the dance? Sir, we cannot allow you, it is against the law.

LOLA. The Cuban Club we built. We must go back. Down to the last grandchild.

CONSUELO. Color is color, but my boys are Cubans, none of these American Negroes. Even if they were born here. (3)

En cierto modo, este tópico del regreso que se reitera a través de la obra, el que presentimos de antemano que no se va a llevar a cabo, no es lo esencial sino la manera en que el conflicto racial estadounidense, con todo su sistema de segregación va a permear el medio ambiente cubano y convertir 
a los cubanos negros en afro-americanos ante los ojos de sus mismos compatriotas. El tema es por cierto álgido para esta comunidad porque cuando Martí la visitó en 1892 escogió abiertamente y hasta de manera arbitraria quedarse en la casa de una familia negra, los Pedraza, en vez de ir a un hotel. Y su primera salida calle arriba y calle abajo a saludar a los vecinos la hizo de brazo de la misma Sra. Pedraza. Por otra parte, la reacción de Lola, cuando exclama: "That hovel of a club giving itself airs! As if it were one of the grand ballrooms of old Havana" (4), nos introduce a otro leitmotif que se repite a través de la obra, y es que Lola viene del mundo de la aristocracia, de los bailes del Palacio del Gobernador, aunque caída en desgracia por su obvio desliz. Por lo tanto, lo que no le perdona el marido, nacido en Cayo Hueso en medio de una familia de artesanos tabacaleros, es precisamente su alta alcurnia. Como microcosmo de la lucha de clases que se perfilaba en ese momento a lo largo del continente latinoamericano, con la mencionada entrada en grande de las varias teorías de izquierda europeas, Yglesias logra plasmar esa dialéctica entre el amor y el odio que muchas veces forma parte del mismo tinglado ideológico. Gustavo es anarquista declarado, insigne sindicalista y líder en la tabaquería; sin embargo, habla y se comporta como si fuera un pequeño burgués. Está siempre preocupado por las apariencias, por conservar el aspecto formal del lenguaje y los modismos - de paso, aunque los personajes deben hablar con el acento neutro inglés de la Costa Este de Estados Unidos, por indicación expresa del autor, se supone que están hablando en perfecto castellano-, por guardar las buenas costumbres (su mujer no lo puede besar en público y los jóvenes no salen a la calle sin chaperones, etc.) y a pesar de los "antecedentes corruptos" de su mujer, se jacta de ser ella su "joya más preciada". Lola, de hecho, vendió sus últimas joyas, a espaldas del marido, durante una larga huelga que duró meses, aunque queda claro que su tesoro más valioso es la bandera que hizo para que su hija Titi se la entregara a Martí durante su visita (lo que es una anécdota real). Martí besó la bandera y se la devolvió a la niña aduciendo que estaba mejor en las manos del futuro de Cuba que en las propias.

Hay, como vemos, varios mundos que se yuxtaponen como círculos viciosos de los que no pueden sustraerse estos personajes en el momento de crisis que visita la obra; para empezar, el de Lola en la Cuba de la sociedad aristocrática habanera, razón por la cual Gustavo nunca aceptaría un regreso porque también, de paso, para él, Cuba es donde viven los cubanos:

GUSTAVO. Nobody wants to go back to Cuba from Ybor City.

LOLA. Where did you get that idea? 
GUSTAVO. When I was a kid, I used to think Cuba was where Cubans lived. I was almost ten before I learned that Key West wasn't Cuba. I thought I was living in Cuba because my father, my mother, all my uncles, everyone but few Spaniards, said they were Cubans... (25)

Por otra parte, su impresión de Cuba cuando finalmente la visitó no cambió en mucho su opinión:

GUSTAVO. It turned out to be very much like Key West... Except it was the Spaniards who ruled there. (26)

Al final de la obra, Alejandro, el yerno, cuyo comportamiento se vuelve cada vez más errático (en una ocasión cree que es la re-encarnación misma de Changó), es enviado al Hospital Municipal de Tampa en donde, como dice Consuelo, "nadie habla español, por lo tanto van a pensar que no tiene todas sus facultades. Ellos creen que nosotros todos estamos tocados" (61), en su camino al destino final Chattahoochee, del que saben todos que no volverá. Es un sitio terminal del que aparentemente no regresa nadie, que se va ampliando hasta cubrir a todo el país, ante el ya ineludible como imposible regreso a la isla y en vista a que un día se dé la posibilidad de que sus nietos no sepan quién fue José Martí:

LOLA. We've created an American family_and we can't uproot them.

GUSTAVO. We won't tell them they're Americans.

LOLA. For once you're right—we'll allow no talk about it.

GUSTAVO. Our grandchildren will speak English.

LOLA. Several already do.

$\ldots$

LOLA. I think I hear them (the grandchildren).

GUSTAVO. What have we done?

LOLA. We've committed them to Chattahoochee. God help them. (91)

En The Dictatorship of the Proletariat, la segunda obra, encontramos a la misma familia diez años después. De Alejandro, sabemos que murió en la institución mental; a Ramón lo aqueja una enfermedad al parecer incurable que lo lleva a la parálisis (y a su prematura muerte, como sabemos que sucedió con el padre de Yglesias) y Leonora queda con dos hijos menores a su cuidado. Entra a colación la hija de Titi, Chela, ahora de 18 años y embarazada de Felix, su novio, convencido e impetuoso sindicalista. Está a punto de dar a luz y la familia todavía no se ha dado cuenta de su estado. 
Estamos de nuevo ante una situación de crisis pues unido a las eventualidades domésticas (el parto de Chela que se viene encima y el empeoramiento de la salud de Ramón) esa noche habrá una votación importante de los tabacaleros para ver si van a la huelga o no. De paso, entre los tópicos a discutirse en la reunión del sindicato está el de si pueden tener lectores en un sitio designado durante todos los días durante la huelga. La acción abre, como en la obra anterior, en la cocina de la casa de los Milián, a la que llegan un vecino, Alfonso el siciliano, notoriamente anarquista, y su mujer Matilde, quien teme que lo deporten a "Rusia" por sus excesos. Entre la vida que se va (Ramón) y la que llega, suceden las conversaciones que oscilan entre el compromiso político de los personajes - se discuten abiertamente las diferencias entre el anarquismo y el comunismo-y las cuestiones más íntimas ventiladas en medio del vecindario, brindándonos ineludiblemente esa impresión del "solar" tan afín a no pocas obras dentro de la dramaturgia cubana, de dentro y de fuera (ver Montes Huidobro 323). Ahora si, por un lado, se percibe un tono elegíaco a la figura del padre enfermo, "un buen obrero" en toda la extensión de la palabra, en el sentido de que no sólo era un buen trabajador sino por encima de todo un buen sindicalista (Yglesias: "The 'good' referred to his relationship with workers as a group" ["Un Buen Obrero", 50])—es él quien aunque impedido de asistir decide votar a favor de la huelga arrastrando a los otros-, hay un esfuerzo por darnos el retrato de una clase trabajadora diferente, si no educada en un sentido tradicional formal por lo menos sí ilustrada y hasta versada en las corrientes doctrinarias de la época.

El segundo acto tiene lugar diez meses más tarde, lo que llevan de huelga. El ambiente, al contrario del primer acto, que era un tanto triunfalista ante la decisión del paro, ahora es derrotista. Los propietarios de las tabacaleras ni se han dignado a reunirse con los trabajadores; el hambre y el cansancio apremian. Son diez meses de ollas en común, ingiriendo "grits, of beans and rice" (52). La alternativa humillante para todos es volver al trabajo, prácticamente a suplicar que se los devuelvan, al votar para finalizar la huelga. Las conversaciones que se suscitan, especialmente entre Felix, el novio de Chela apodado el "Bolshevita", y el siciliano Alfonso, son de particular importancia por introducir el autor un asunto discordante en medio de las férreas convicciones políticas que parecen todos poseer, respecto al concepto del "surplus value" (plusvalía) tan usado por Marx en sus ensayos sobre la economía política: 
FELIX. I didn't get it. Karl Marx says that this price that those big shots pay for cigars in the stores in New York and London and Paris is what the cigars are really worth? He says that?

ALFONSO. Not in those words, but yes. (48) No satisfecho con la respuesta, Felix insiste:

FELIX. It can't be, Alfonso. Everybody knows that they charge whatever they like. Rich men don't look at the price of things. (48)

De ahí, Alfonso pasa a explicar que ese precio agregado representa el "surplus value" del que hablaba Marx, o sea las "ganancias" que el "capitalista" obtiene al "interferir entre el trabajador y el consumidor", a lo que Felix responde:

FELIX. Thieves, that's what the capitalists are. Marx knew them well, I tell you. Stealing from the consumer.

ALFONSO. No, from the worker.

FELIX. Oh, from the worker too, yes.

ALFONSO. No, from the worker only. (50)

A pesar de la respuesta de Alfonso, la cuestión no queda zanjada y Felix vuelve a las andadas con una pregunta que de manera retórica, aunque bastante real, se queda sin respuesta:

FELIX. I can't believe that Marx says that those inflated prices are the real value of the cigars.

ALFONSO. He did.

FELIX. Aren't prices going to come down when socialism is in power? (59)

Al final de la obra, cuando ya cruzan la puerta para ir a la reunión del sindicato aparece un grupo armado y encapuchado del KKK, del que logran atrapar a uno en medio de la reyerta que tiene lugar. Al quitarle la capucha resulta ser Fernando Pla, el "primer policía latino" de Tampa, al servicio de la represión. Bajo la premisa de que lo obligaron a unirse a ellos, se excusa vacilante para salir ileso del encuentro. Es evidente que Yglesias después de todo no está interesado en brindarnos la imagen de una comunidad ideológicamente uniforme a ultranza porque, de hecho, no lo era. Es más, el mismo Martí sufrió un atentado contra su vida durante su visita a Tampa en 1892, en manos de dos de sus compatriotas, cuando trataron de envenenarlo con un vino adulterado (ver Mañach).

Otro tema que sale a relucir en esta obra es la participación femenina siempre relegada a un lugar subalterno y acompañada con las generalizacio- 
nes de rigor como el mismo Felix comenta, refiriéndose a la atención que prestaban las trabajadoras a las lecturas:

FELIX. I don't know about the women strippers. All the noise in the factory comes from their end. They drown out the reader, especially when he's reading from the newspapers. Women! They only stay quiet for the book reading and then it had better be a novel, not something solid and worthwhile like Kropotkin [...]. (8)

Sin embargo, Leonora hace bien en recordarle a su padre Gustavo la importancia que tuvo la presencia femenina en los conflictos laborales de las tabacaleras, a lo largo de su producción y en diferentes sitios, en la persona de la pionera y dramaturga, de paso, Luisa Capetillo (1879-1922). ${ }^{16}$

GUSTAVO. Got any last minute instructions for us, Leonora?

LEONORA. Go on, make fun of me-you could use a woman in your committee. I wish that Capetillo woman from Puerto Rico was still here. She was the best orator in Ybor City. (8)

Aunque después de la Segunda Guerra Mundial se empezaron las negociaciones con los sindicatos, el advenimiento de la época macartista diezmó el liderazgo de los tabacaleros al poner en listas negras a varios de sus dirigentes. Pero quizás el golpe de gracia lo recibió la industria cuando llegó el embargo después de la Revolución en 1959 y no se pudo importar más tabaco de Pinar del Río.

En la tercera obra de la trilogía, You Don't Remember?, regresa el protagonista / autor a su comunidad en 1978, en la que, a juzgar por el mismo obituario que lleva consigo, será su última visita. Las conversaciones tienen lugar en el tradicional porche en donde se reúnen la familia y los vecinos a comentar los sucesos del día. Quedan la madre y su hermana Celia, con su marido Cuco, aunque también aparece Oscar, su primo hermano más cercano y se hace mención del resto de la numerosa familia, que se hace sentir a través de la inagotable interrupción del timbre telefónico a lo largo de la obra. También entra en el reparto su hijo Rafa y su novia Leslie, quienes para el escándalo soterrado de toda la familia viven en abierto concubinato. Fuera de la familia aparece Rosa, una vecina negra, quien comparte las vicisitudes de los Milián como para reforzar la idea de convivencia racial que desde el principio anima a la trilogía. El protagonista / autor recorre sus pasos para eminentemente, por un lado, asegurarse que no se quedó algo en el tintero, o sea en la memoria de su madre, que él no haya tenido noticia y, en segundo lugar, reafirmar su misión como cronista de su gente y asegurarle un lugar ya no sólo en la historia de una comunidad (la cubano-americana) sino en el 
tejido multi-cultural de una nación que empezaba a reconocer su pluralidad étnica. ${ }^{17} \mathrm{Al}$ igual que Dickens y Víctor Hugo (mencionados en la obra), y tal como señala el personaje a su madre, su objetivo, a través de su obra literaria y periodística, fue que Ybor City no cayera en el olvido y que sus tabacaleros pasaran a la historia como la "vanguardia de la clase trabajadora norteamericana" (36). A lo que la madre sin pensarlo dos veces replica: "We are not Americans". Es la respuesta del primero la que seguramente quedará mucho tiempo con nosotros después de leída o vista la obra: "Yes, you were, you damn well were. That's my point. That we were the real Americans. The real heirs of the radical absolutionists" (énfasis del autor, 36).

Leídos estos testimonios, por momentos íntimos, sobre Yglesias y su familia, en esa época plagada de conflictos laborales, sociales, raciales y políticos que surtió el contexto de la vida de estos singulares tabacaleros, una cosa nos queda clara y es que del marco ideológico al que nos referimos desde un principio con el que Yglesias trató de darle un sentido a su vida, y a su obra, o sea del anarquismo, escoge tanto él como sus personajes la libertad y en última instancia, a pesar de todas las diferencias de rigor, la inclusión.

\section{Festival Internacional de Teatro Hispano de Miami, FL}

\section{Notas}

1 Jose Yglesias no marcaba el acento que acostumbra llevar su nombre en español; respetamos su decisión a lo largo de nuestro ensayo. Ybor City es un vecindario de la ciudad de Tampa, en la Florida.

Una primera versión de este ensayo se leyó durante el congreso "Celebrando a Virgilio Piñera", organizado por Matías Montes Huidobro y Yara González, que se celebró en la Universidad de Miami, FL, el 12-15 de enero de 2012.

2 “The theater's immediacy, its unmediated confrontation with the audience's sensibilities, is the best vehicle for those Latins from Ybor City" (Yglesias, cit. por Ingalls, "The Life", 24).

3 Entre las novelas autobiográficas que sirven de base a las dos primeras obras de la trilogía que contemplamos aquí, se encuentran The Truth About Them (1971), sobre el fracaso de la huelga de 1931 en defensa de los lectores, en la que "retrata tres generaciones de una familia de Ybor City y también provee una historia anecdótica de la comunidad latina de Tampa" (Ingalls, "The Life", 23); Home Again (1987) en la que el personaje protagónico, un hombre desahuciado, regresa por última vez a Ybor City y Tristán and the Hispanics (1989) que "trata sobre su propia inmortalidad y el legado literario y familiar que dejó atrás" (24).

4 Recientes pasos para llenar este vacío lo suplen las investigadoras Magaly Muguercia con su libro Teatro latinoamericano del siglo XX: Primera modernidad (1900-1950) (2010) y Marina Lamus Obregón con Geografias del teatro en América Latina: Un relato histórico (2010).

5 Se estima que de 720 personas que habitaban Tampa en 1886, para 1890 ya la cantidad había aumentado a 5,532. En 1910 se registran 37,782 de las cuales unos 10,000 trabajaban para los tabacaleros (Tinajero). 
6 El nombre de "Jim Crow" se deriva de una canción de los minstrels norteamericanos de los 1830s, en la que el intérprete blanco se pintaba la cara de negro para representarlo de manera paródica. Al pasar el tiempo, llegó a significar el sistema racial segregacionista que imperó sobre todo en el sur de Estados Unidos y los estados fronterizos con el norte, después de la guerra civil, o sea a partir de 1870 hasta los años sesenta del siglo XX con el advenimiento de las luchas de los derechos civiles que terminaron con las leyes y supuestamente las prácticas de tal sistema.

7 De acuerdo a Yglesias, eventualmente "only the old-timers among Cuban blacks still worked elbow to elbow with whites in the cigar factories". De ahí, fueron los primeros en ser despedidos y no fueron empleados más ningún aprendiz de color: "they were pushed down to the level of native-born American blacks. In time, finally, the cigarmaker's children took on the racism of the crackers" ("José Martí, 68).

8 Yglesias: "Everybody gave ten percent of their pay check for the Republic. It was wild. The total community was with Loyalist Spain. They used to send enormous amounts of things. It was totally organized. The song 'No pasarán' that was taken to be Spanish was really by a Tampa cigar maker" ("The Depression Years", 41).

9 Conocido como "Los pinos nuevos", Martí dio este discurso el 27 de noviembre de 1891 en el Liceo Cubano en Tampa, rememorando los hechos sangrientos acaecidos el 27 de noviembre de 1871 cuando ocho estudiantes de medicina fueron asesinados por el régimen colonial español en La Habana. Francisco María Gonzáles lo registró taquigráficamente. Este es uno de los portales en el Internet en el que se puede leer el texto completo: http://www.damisela.com/literatura/pais/cuba/autores/marti/ discursos/1891 11 27.htm.

${ }^{10}$ El personaje histórico de Martí es una constante en el teatro escrito fuera de Cuba (AbdalaMartí de Iván Acosta, Un hombre al amanecer de Raúl de Cárdenas y A Burning Beach de Eduardo Machado son ejemplos pertinentes).

11 Yglesias: "These cigarmakers never thought of America as a place they have come to for freedom and democracy. Indeed, they were the civilized; the Americans [were the] barbarians" (cit. por Ingalls, "Jose Yglesias", 80).

12 En 1993, conocí brevemente a Jose Yglesias, en Nueva York, un personaje inolvidable empezando por su tamaño (porque medía 6 pies, 4 pulgadas) y su bonhomía (era ese tipo de persona que cuando sonreía el mundo sonreía con él). Me entregó una copia en manuscrito de su trilogía sobre Ybor City con una nota que decía "I like to say they are related plays, rather than a trilogy-you'll see why". Él murió poco tiempo después de una larga enfermedad. De hecho, la última obra de la trilogía-escrita en 1989- habla de su próxima defunción.

Las tres obras principales que discuto en este estudio siguen inéditas; todas las citas vienen de estas copias de los manuscritos que me dio Yglesias.

13 Valga señalar que pensamos que sería erróneo juzgar la sociedad, tal como se refleja en las obras, de una manera maniqueista. A pesar de la referencia al racismo sin medida que de hecho estaba teniendo lugar en el sur del país con la entrada ya no simbólica sino muy real del Ku Klux Klan-clave, por mencionar una instancia, para la deportación del famoso tío Francisco Milián (que luego de su regreso llegó a ser alcalde) - , no es por tanto una pintura en blanco y negro. En la primera pieza de la trilogía, por ejemplo, se hace mención en forma laudatoria al líder sindical socialista Eugene Debs (1855-1926), quien perteneció al partido demócrata y llegó a ser nominado al Premio Nobel de la Paz.

14 Yglesias dejó una cuarta obra titulada New York 1937 (1990) que no se centra alrededor de Ybor City y sus habitantes aunque deducimos por la fecha que se refiere al compromiso de la comunidad latina con la Guerra Civil Española. Hasta donde nuestros conocimientos alcanzan, la trilogía a la que nos referimos aquí sólo ha recibido varias lecturas dramatizadas, una de ellas en el Coconut Grove Playhouse, de Miami, bajo la dirección de Arnold Mittelman, en 1989.

15 Yglesias: "I should like in my work to bring into clear view the moral views and approach to experience of workers, something which seems to me missing from most fiction" (cit. por Ingalls, "The Life", 8). 
${ }^{16}$ Los ensayos de Luisa Capetillo están compilados en el volumen A Nation of Women: An Early Feminist Speak Out. Trad. Alan West-Duran e introducción de Felix V. Matos Rodriguez (Houston: Arte Público P, 2004). Ver también los libros de Norma Valle-Ferrer, Luisa Capetillo: Historia de una mujer proscrita (San Juan: Editorial Cultural, 1990) y Luisa Capetillo, Pioneer Puerto Rican Feminist (New York: Peter Lang, 2006).

17 El tema del regreso a visitar parientes para cotejar ideologías, e historias familiares, es casi un lugar común en la dramaturgia cubana escrita fuera de la isla, para mencionar tan sólo unos nombres traemos a colación a Raúl de Cárdenas, René Alomá, Eduardo Machado, Carmelita Tropicana (Alina Troyanos) y Nilo Cruz, entre otros.

\section{Obras citadas}

Bourdieu, Pierre. Distinction: A Social Critique of the Judgement of Taste. Trans. Richard Nice. Cambridge, MA: Harvard UP, [1984], 2002.

Espinosa Domínguez, Carlos. "Una dramaturgia escindida". Teatro cubano contemporáneo: Antología. Ed. Carlos Espinosa Domínguez. Madrid: Fondo de Cultura Económica, 1991. 13-77.

Garzón Céspedes, Francisco. “José Antonio Ramos: Una línea ascendente de rebeldía”. Latin American Theatre Review 14.2 (Spring, 1981): 5-10.

Ingalls, Robert P. “Jose Yglesias 1919-1995: A Eulogy”. Tampa Bay History 79-81. . "The Life and Work of Jose Yglesias". Tampa Bay History 5-30.

Lamus Obregón, Marina. Geografías del teatro en América Latina: Un relato histórico. Bogotá: Luna Libros, 2010.

Leal, Rine. "La chancleta y el coturno". Teatro Bufo: Siglo XIX. Tomo I. Ed. Rine Leal. La Habana: Editorial Arte y Literatura, 1975. 15-130.

Mañach, Jorge. Martí el Apóstol. Madrid: Editorial Sopena, 1933.

Montes Huidobro, Matías. Cuba detrás del telón IV: Insularidad y exilio (1969-1979). Miami: Ediciones Universal, 2010.

Muguercia, Magali. Teatro latinoamericano del siglo XX: Primera modernidad (1900-1950). Santiago: RIL Editores, 2010.

Ríos, Marcela de los. Perfil del teatro de la Revolución Mexicana. New York: Peter Lang, 1993.

Tampa Bay History 18.1 (Spring/Summer 1996). Versión en línea. http://www. hillsborough.communityatlas.usf.edu/upload/documents/RememberinJoseYglesias.pdf

Tinajero, Araceli. El lector de tabaquería: Historia de una tradición cubana. Madrid: Verbum, 2007.

Yglesias, Jose. "The Bittersweet Legacy of la Madre Patria". Tampa Bay History 53-58. Reimpresión de Nuestro 2 (abril 1978): 24-28.

. "The Depression Years in Ybor City". Tampa Bay History 40-43. Reimpresión de Hard Times: An Oral History of the Great Depression, de Studs Terkel. New York: Pantheon, 1970. 109-12. 
. Home Again. Westminster, Maryland: Arbor House Publishing, 1987. . "José Martí in Ybor City". Tampa Bay History 59-71. Reimpresión de José Martí in the United States: The Florida Experience. Luis A. Pérez, ed. Tempe: Arizona State University Center for Latin American Studies, 1995. . "A Trilogy Takes its Playwright Home Again". The New York Times, April 23, 1989. Section H, 5.

. Tristán and the Hispanics. New York: Simon and Schuster, 1989.

. The Truth About Them. New York: World Publishing, 1971.

. "Un Buen Obrero: A Short Story". Tampa Bay History 47-52. Reimpresión de New Masses 61 (Nov. 26, 1946): 17-19. 